\title{
Implementation of Community-Based Resource Referrals for Cardiovascular Disease Self-Management
}

\author{
Emily Abramsobn, $M P H^{1}$ \\ Megan DePumpo, $\mathrm{AM}^{1}$ \\ Kelly Boyd ${ }^{1}$ \\ Tiffany Brown, MPH ${ }^{2}$ \\ Milton F. Garrett, III $^{2}$ \\ Abel Kbo, MD, MS, FACMI ${ }^{2}$ \\ Chenab Navalkba \\ Kelsey Paradise ${ }^{1}$ \\ Stacy Tessler Lindau, MD, MAPP \\ 'The University of Chicago, Chicago, \\ Illinois \\ ${ }^{2}$ Feinberg School of Medicine, North- \\ western University, Chicago, Illinois
}

\begin{abstract}
PURPOSE Describe primary care practices' implementation of CommunityRx-H3, a community resource referral intervention that utilized practice facilitators to support cardiovascular disease (CVD) prevention quality improvement.
\end{abstract}

METHODS Qualitative focus groups were conducted with practice facilitators to elicit perceptions of practices' experiences with CommunityRx-H3, practice-level factors affecting, and practice facilitator strategies to promote implementation. Qualitative data were analyzed using directed content analysis. The Consolidated Framework for Implementation Research was applied deductively to organize and interpret findings.

RESULTS Fourteen of all 19 practice facilitators participated. Practice facilitators perceived that staff attitudes about connecting patients to community resources for CVD were largely positive. Practices were already using a range of non-systematic strategies to refer to community resources. Practice-level factors that facilitated CommunityRx-H3 implementation included clinician "champions," engaged practice managers, and a practice culture that valued community resources. Implementation barriers included a practice's unwillingness to integrate the intervention into existing workflows, limited staff capacity to complete the resource inventory, and unavailability or cost of materials needed to print the resource referral list ("HealtheRx-H3"). Practice facilitator strategies to promote implementation included supporting ongoing customization of the HealtheRx-H3 and material support. Practice facilitators felt implementation would be improved by integration of CommunityRx-H3 with electronic medical record workflows and alternative methods for engaging practices in the implementation process.

CONCLUSIONS Practice facilitators are increasingly being utilized by primary care practices to support quality improvement interventions and, as shown here, can also play an important role in implementation science. This study yields insights to improve implementation of community resource referral solutions to support primary care CVD prevention efforts.

Ann Fam Med 2020;18:486-495. https://doi.org/10.1370/afm.2583.

\section{INTRODUCTION}

7 he Million Hearts campaign was launched in 2012 to prevent $1,000,000$ heart attacks by 2017 by promoting ABCS (appropriate aspirin therapy, blood pressure control, cholesterol management

Conflicts of interest: S.T. Lindau is founder and co-owner of NowPow LLC. Neither the University of Chicago nor the University of Chicago Medicine is endorsing or promoting any NowPow entity or its business, products, or services. All other authors bave no conflicts of interest to declare.

\section{CORRESPONDING AUTHOR}

Emily Abramsohn, MPH

5841 S. Maryland Ave, MC 2050

Chicago, IL 60637

eabramsohn@bsd.uchicago.edu and smoking cessation) and advancing evidence-based guidelines for cardiovascular disease (CVD) prevention. ${ }^{1,2}$ Most CVD in the United States is identified and treated in small primary care settings where barriers to implementation of evidence-based guidelines include less meaningful use of electronic medical records (EMR) and issues with staff retention. ${ }^{3,4}$ EvidenceNOW, a nationwide Agency for Healthcare Research and Quality (AHRQ) initiative, supports regional cooperatives of small and mid-sized primary care practices (generally those with $<20$ primary care clinicians) to provide evidence-based CVD care by providing datadriven quality improvement (QI) strategies, practice facilitation, and other supports. ${ }^{5,6}$ 
Pay-for-performance payment models are incentivizing health care professionals caring for people with CVD to implement systematic strategies to promote wellness and disease self-management, including referral to community-based programs and services. ${ }^{78}$ Primary care practices are increasingly engaging practice facilitators, a role that aims to support and improve practices' internal capacity to support QI interventions ${ }^{9-11}$ and reach important operational and clinical goals. The mode and effectiveness of external facilitation varies, ${ }^{12-14}$ but is generally effective in promoting improvements in chronic disease outcomes, including $\mathrm{CVD}_{1}{ }^{15}$ and meaningful use of electronic medical record systems. ${ }^{16}$ Practice facilitators have also been engaged in implementation of the Chronic Care Model ${ }_{1}^{13}$ a guide for delivering effective care for patients with chronic illness, which requires care coordination and effective delivery of community resource referrals. ${ }^{17,18}$

Healthy Hearts in the Heartland (H3), the Midwestern EvidenceNOW cooperative, was designed to evaluate small primary care practices' QI improvement strategies to address the ABCS of heart health. ${ }^{5,6,19}$ All practices enrolled in $\mathrm{H} 3$ were assigned a practice facilitator to help support implementation of 35 QI strategies including point-of-care (POC) (eg, clinical decision support, ABCS performance reports) and population management (PM), which included CommunityRx-H3. Practice facilitators were trained to engage practices, conduct QI work, and use administrative tools for tracking and documentation. ${ }^{20}$ CommunityRx-H3 was an adaptation of CommunityRx, an evidence-based EMR-integrated community resource referral system developed and tested with more than 113,000 patients (nearly 30\% with a CVD-related condition) in primary care and emergency care settings. CommunityRx used evidence-based algorithms to auto-generate a personalized community resource referral list called a "HealtheRx." ${ }^{21}$ Studies from a prior pragmatic trial of CommunityRx delivered to middle age and older primary care and low-acuity emergency care patients identified increased knowledge of and self-efficacy for finding healthful community resources among those who received 1 or more HealtheRx compared with controls. ${ }^{22,23}$ Although there is a growing body of evidence about clinic-based interventions to facilitate community resource referrals for disease self-management and selfcare, ${ }^{24-26}$ and large health systems are rapidly adopting community resource referral technologies ${ }_{1}{ }^{27}$ little is known about small primary care practices' implementation of community resource referral strategies. ${ }^{28,29} \mathrm{To}$ address this gap, this study applies the Consolidated Framework for Implementation Research (CFIR) ${ }^{30}$ to investigate practice facilitator perceptions and observations about CommunityRx-H3 implementation.

\section{METHODS}

\section{Intervention}

The $\mathrm{H} 3$ randomized controlled trial assigned practices to implementation of only POC strategies for QI or implementation of both POC and PM strategies. The study included 1 year of implementation followed by a 6 -month sustainability period. ${ }^{6}$ Practice facilitators were trained to provide education on best practices and implement selected QI strategies, including CommunityRx-H3, for practices randomized to $\mathrm{POC}+\mathrm{PM}$. For practices opting to implement CommunityRx-H3, practice facilitators were trained to support practices' use of an online resource inventory (Figure 1). Practice facilitators were trained to observe QI implementation processes and dynamics. H3 practices chose how often and in what capacity they worked with practice facilitators. Practices in the POC+PM arm reported an average of 6 visits from their practice facilitator over the implementation period and an average of 2 remote contacts. ${ }^{31}$

In prior implementations, ${ }^{21,23,32}$ CommunityRx integrated with EMR platforms to auto-generate the HealtheRx. Due to variation in H3 practices' EMR platforms, availability, and use, and barriers to execution of institutional agreements, the $\mathrm{H} 3$ implementation of CommunityRx was not integrated with practices' EMRs. Instead, a HealtheRx-H3 was developed for each practice site, listing CVD prevention resources near or at each practice location. ${ }^{28}$ To generate each HealtheRx-H3, practices were invited to complete an online inventory of CVD prevention resource information (name, contact information, operating hours, fees, available services) (Table 1). Each HealtheRx-H3 was generated from the resource inventory and included an infographic with local countyand state-level ABCS-related statistics (eg, rates of hypertension-related hospitalization, costs attributable to CVD-related admissions, CVD-related death rates, and local tobacco quit line use rates [Figure 2]).

Practice facilitators reviewed the HealtheRx-H3 with practice staff for feedback and relayed requested changes to the research team for iteration. Practice facilitators educated clinical staff to print and deliver the Healthe Rx-H3 at the point of care to any patient with diabetes and/or hypertension, or who would benefit from self-care resources for heart health.

\section{Study Design and Participants}

This study used mixed methods to characterize implementation of CommunityRx-H3 from the perspective of practice facilitators as expert informants. After the QI intervention was complete (September 2017), practice facilitators participated in focus groups that elicited their perceptions of practices' experiences with CommunityRx-H3, factors related to practices' ability 
Figure 1. Practice facilitator training included educating practices about and strategies to support resource inventory completion.

\section{STEP 1: EDUCATE}

PFs were trained to educate $\mathrm{H} 3$ practices about the value of completing the resource inventory with places and services provided either:

ON SITE at H3 practice; example services include:

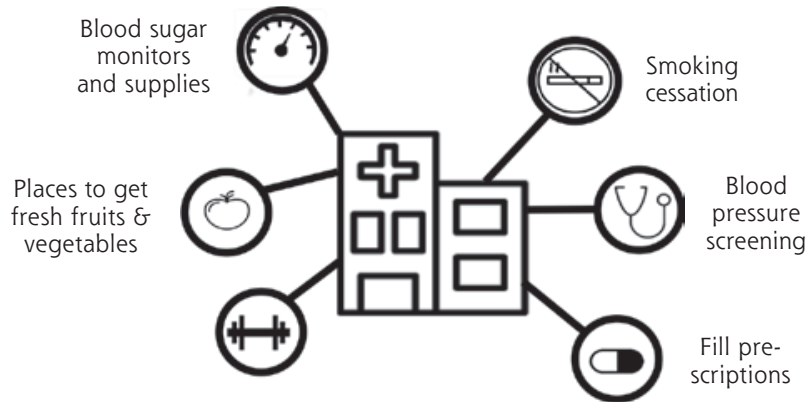

OFF SITE in community; example places include:

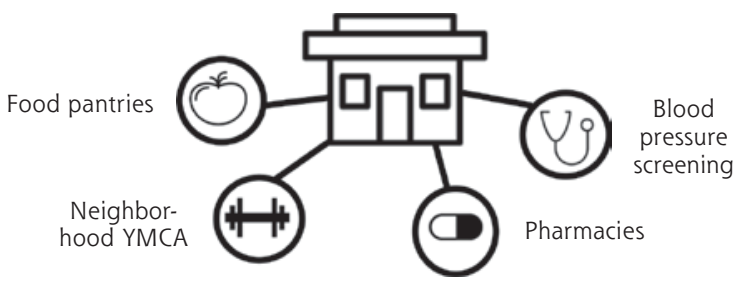

STEP 2: SUPPORT

PF identifies practice staff who are most knowledgeable about practice and community resources for CVD prevention. PF provides staff with access to resource inventory link and instructions for completion.

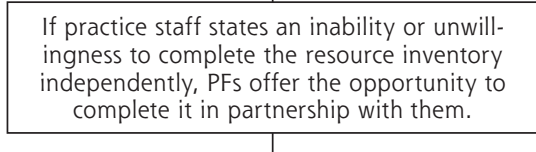

If practice staff declines to complete the inventory, PFs complete the inventory using a list of resource referrals provided by the practice.

If practices are unable to provide a list of resource referrals, research staff completes the resource inventory using an Internet search to identify CVD-related resources located near the practice location.

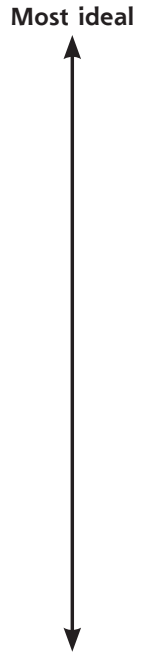

Least ideal

CVD = cardiovascular disease; $\mathrm{H} 3=$ Healthy Hearts in the Heartland; PF = practice facilitator.

to implement CommunityRx-H3, including facilitators and barriers, and strategies used by practice facilitators to facilitate implementation. Practice facilitators' ideas about how to optimize the CommunityRx-H3 intervention emerged organically in focus group discussions. Practice facilitators who participated in the focus groups completed a self-administered survey immediately before the focus group session. H3 practices completed practice surveys at baseline. All participants consented to participation in this study. The University of Chicago Institutional Review Board approved this study.

\section{Data Collection and Analysis}

Focus groups were conducted using a semi-structured interview guide (Supplemental Appendix 1, available at https://www.AnnFam Med.org/content/18/6/486/suppl/ DC1/) at a regularly scheduled, in-person meeting of all practice facilitators following completion of the QI intervention. The focus group method is efficient and well-suited to elicit similarities and differences in experiences and observations among a relatively homogenous group (practice facilitators were generally similar in their education, training, and
Table 1. Community Resources Indicated for Promotion of the ABCS and for Addressing Comorbidities

\begin{tabular}{|c|c|c|c|c|c|}
\hline \multirow[b]{2}{*}{ Indicated community resource referrals } & \multicolumn{4}{|c|}{$\begin{array}{c}\text { ABCS } \\
\text { Recommendations }\end{array}$} & \multirow[t]{2}{*}{$\begin{array}{c}\text { Addressing } \\
\text { Comorbidities }\end{array}$} \\
\hline & A & $\mathrm{B}$ & $\mathrm{C}$ & S & \\
\hline Blood pressure monitors for sale or use on-site & & $x$ & & & \\
\hline Blood glucose monitors for sale or use on-site & & & & & $x$ \\
\hline Fill prescriptions & $x$ & $x$ & $x$ & $x$ & $x$ \\
\hline Diabetes education classes & & $x$ & $x$ & $x$ & $x$ \\
\hline Health education classes & $x$ & $x$ & $x$ & $x$ & $x$ \\
\hline $\begin{array}{l}\text { Individual classes or 1-on-1 smoking cessation } \\
\text { counseling }\end{array}$ & & & & $x$ & \\
\hline Individual mental health counseling & & $x$ & & $x$ & $x$ \\
\hline Stress management classes & & $x$ & $x$ & $x$ & $x$ \\
\hline Cooking or healthy eating classes & & $x$ & $x$ & & \\
\hline Weight loss classes & & $x$ & $x$ & & \\
\hline Group exercise or walking groups & & $x$ & $x$ & & \\
\hline
\end{tabular}


experience sets). ${ }^{33}$ Fourteen of 19 practice facilitators employed by the $\mathrm{H} 3$ study were in attendance and consented to participate. Practice facilitators were counted off sequentially and were assigned, according

Figure 2. Example generic practice-specific HealtheRx-H3.

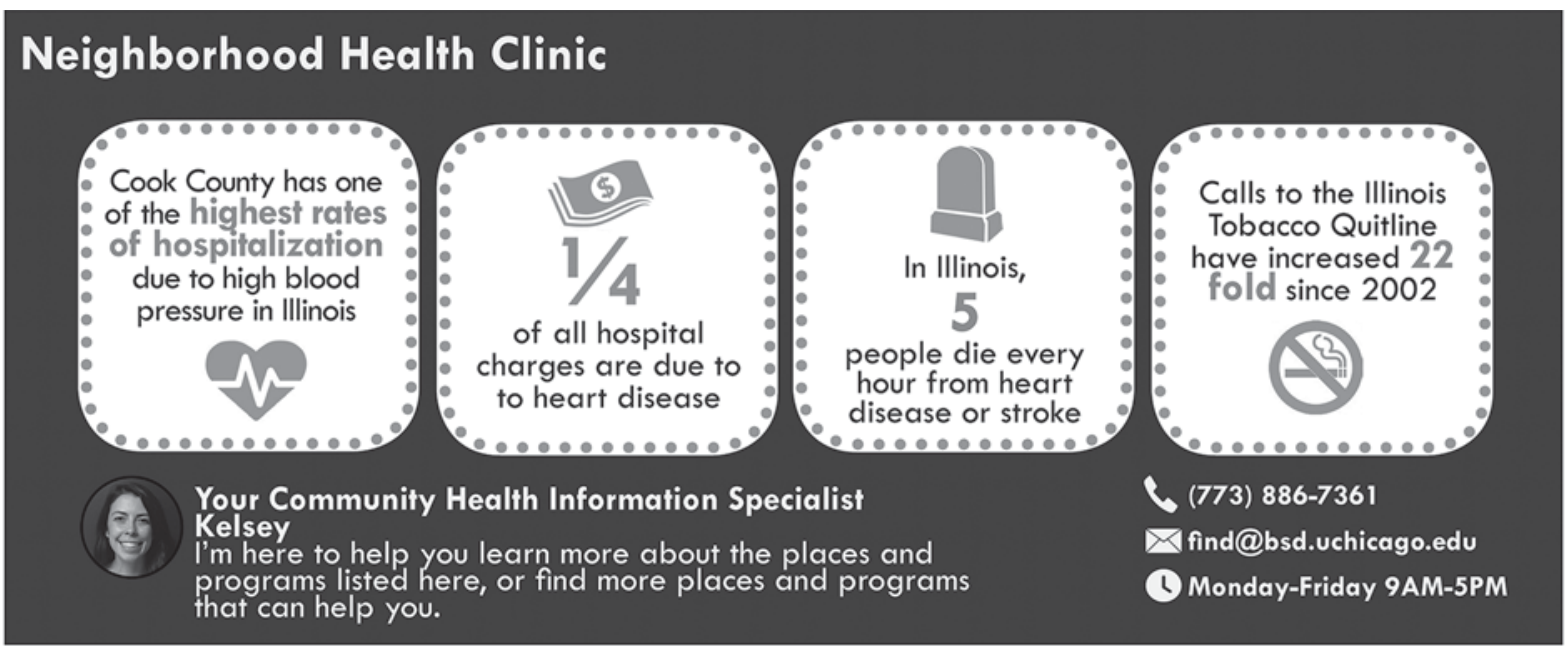

Resources

1 Neighborhood Health Clinic

600 N Prairie St, Chicago IL, 60611 | (312) 735-2980

Office Hours:

Monday-Wednesday: 8AM-7PM

Thursday-Friday: 8AM-5PM, Saturday: 8AM-12PM

Sunday: Closed

Fees: Insurance, Self Pay

- Individual counseling

- Blood pressure screenings

Walgreens

100 N Main, Chicago IL, 60611 | (630) 342-5377

Store Hours:

Monday-Sunday: Open 24 hours

Pharmacy Hours:

Monday-Friday: 8AM-8PM, Saturday-Sunday: 9AM-6PM

Fees: Insurance, Self Pay

- Aspirin

- Blood pressure screenings

- Blood sugar monitors and supplies

- Fill prescriptions

3 Neighborhood YMCA

34 E Fifth St, Chicago IL, 60611 | (224) 616-8806

Hours:

Monday-Friday: 8AM-8PM, Saturday-Sunday: 9AM-6PM

Fees: Self Pay, Sliding Scale

- Walking groups

- Group exercise classes

- Individual exercise classes
Important Numbers \& Websites

Illinois Tobacco Quił Line

Call (866) 784-8937 or text QUIT to 4-7878

Weight Loss, Nutrition, Fitness

Weight Control Information Network:

(800) 860-8747 | M-F 7:30AM-4PM CST

24/7 Suicide Prevention \& Crisis Hotline

Call (800) 273-8255 or text ANSWER to 839-863

\section{4/7 Domestic Violence Helpline}

Call (800) 799-7233 or visit thehotline.org

General Health/Heart Health

American Heart Association:

(800) 242-8721 | M-F 7:30AM-3:30PM CST www.healthfinder.gov or www.heart.org

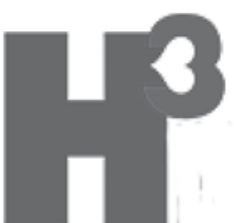

The information provided here is not a rating of quality or an endorsement. This information is provided by Healthy Hearts in the Heartland, the Midwest cooperative of the EvidenceNOW program, supported by grant \#1R18HS023921-01 from the Agency for Healthcare Research and Quality. 
to even or odd number, to 1 of 2 separate but concurrent 1 -hour focus groups, conducted by E.A., C.N., or M.D. and K.B. Two focus groups of 7 each were conducted to enable a meaningful opportunity for each practice facilitator to contribute. ${ }^{34}$ Focus groups were audio-recorded to ensure accuracy of data collection. The research team included practicing physicians and experienced qualitative researchers with expertise in public health, social service administration, medical anthropology, biomedical informatics, health services research and health care delivery science, and information technology interventions.

Focus group data were collected and analyzed using directed content analysis, a method appropriate for use in this study to extend existing knowledge about implementation of the established CommunityRx intervention in a new context. ${ }^{35}$ Directed content analysis derives initial codes and categorizations of codes deciphered from existing literature in order to investigate the concept under study and to structure coding of qualitative data. In an attempt to fully represent both emergent themes and dissenting voices, the individual practice facilitator was the unit of analysis. ${ }^{36}$ Using the focus group guide, codes were defined by researchers in a codebook before data analysis (Supplemental Appendix 2, available at https://www.AnnFam Med.org/content/18/6/486/suppl/DC1/). Because some members of the research team worked directly with practice facilitators to generate their practice-specific HealtheRx-H3, we deidentified focus group transcripts before coding and analysis to avoid potential biases that may arise from this relationship. Initial analysis began with a full read of the transcripts for instances of textual data that aligned with the codes; coding occurred upon second pass review using the codebook. Any textual data that was identified in the first-pass read of the transcript but not coded was given a new code. Two researchers analyzed the data. Because no new perceptions were expressed by the conclusion of either focus group, it was determined that data saturation was reached. ${ }^{37}$ Commonly occurring codes were grouped into categories. Following data collection and analysis, the CFIR was applied deductively to organize and interpret our findings based on the definitions and examples provided in Damschroder et al. ${ }^{30}$ The CFIR consists of 5 domains (intervention characteristics, outer setting, inner setting, characteristics of the individuals involved and the process of implementation) and provides a systematic structure to organize and interpret qualitative data from the focus groups for comparison of findings across implementation studies. ${ }^{30}$ A senior researcher oversaw development of the focus group guide. Another senior researcher reviewed preliminary findings from the research and aided in interpretation of findings in relation to the larger EvidenceNOW research effort. ATLAS.ti version 7.5.18 (Scientific Software Development GmbH) was used for data coding, analysis and textual extraction. Quotes are noted "PFx" where $\mathrm{x}$ is a random number 1-14 assigned to each participating practice facilitator.

Immediately before the start of each focus group, practice facilitators completed a self-administered survey to obtain demographic and occupational characteristics. Clinician and clinical staff with insights into clinical operations at $\mathrm{H} 3$ practices completed a baseline survey querying practice-level characteristics. Responses were summarized and stratified by practice facilitator focus group participation (yes/no) to assess how well represented the $\mathrm{POC}+\mathrm{PM}$ practices were by the practice facilitators who participated. Chi squared tests assessed for associations between practice facilitator participation and practice characteristics. When appropriate, a Fisher's Exact test was used in lieu of parametric test.

\section{RESULTS}

Fourteen of 19 practice facilitators in attendance at the meeting participated in focus groups (Table 2). Practice facilitators were mainly master's- $(n=9)$ or

\section{Table 2. PF-Reported Sociodemographic and Practice Facilitation Characteristics $(n=14)$}

\begin{tabular}{|c|c|}
\hline \multicolumn{2}{|c|}{ Sociodemographic characteristics ${ }^{a}$} \\
\hline Age, y (median, range) & $51(33-64)$ \\
\hline \multicolumn{2}{|l|}{ Sex } \\
\hline Women & $11 / 14$ \\
\hline Men & $2 / 14$ \\
\hline \multicolumn{2}{|l|}{ Race } \\
\hline White & $11 / 14$ \\
\hline Other & $2 / 14$ \\
\hline \multicolumn{2}{|l|}{ Education } \\
\hline Bachelor's degree & $4 / 14$ \\
\hline Master's degree & $9 / 14$ \\
\hline \multicolumn{2}{|c|}{ H3 practice facilitation characteristics } \\
\hline \multicolumn{2}{|c|}{$\begin{array}{l}\text { With whom do you interact at practices } \\
\text { that deliver HealtheRx? }\end{array}$} \\
\hline Physician & $12 / 14$ \\
\hline Office or practice manager & $10 / 14$ \\
\hline Medical assistant & $9 / 14$ \\
\hline \multicolumn{2}{|c|}{$\begin{array}{l}\text { With whom do you work most closely on } \\
\text { the HealtheRx?b }\end{array}$} \\
\hline Office or practice manager & $10 / 14$ \\
\hline Physician & $8 / 14$ \\
\hline Nurse or medical assistant & $6 / 14$ \\
\hline
\end{tabular}


bachelor's-level $(\mathrm{n}=4)$ professionals between the ages of 33-64 years (median aged 51 years). Practice facilitators represented $71 \%$ of $\mathrm{H} 3$ practices assigned to the POC+PM arm (Table 3).

\section{Clinical Practices' Experiences With CommunityRx-H3}

Practice facilitators perceived largely positive staff attitudes about connecting patients to community resources for CVD. At baseline, practice facilitators reported that an array of informal strategies were used to educate patients (eg, staff sharing personal knowledge or using a "green book" (PF7) directory). PF2 noted that some practices, mainly in more rural settings, were using personal knowledge of resources for referrals "but it really wasn't written down" and bought in to the intervention "out of necessity." Practice facilitators felt that practices with positive attitudes about the value of community resource referrals for CVD prevention and management were more likely to see value in the intervention; these practices seemed to practice facilitators to be more likely to engage by requesting customization or changes to the HealtheRx-H3.
Table 3. Characteristics of H3 Primary Care Practices Randomized to the POC+PM Arm, Stratified by PF Representation in the Focus Groups $(n=114)^{\text {a }}$

\begin{tabular}{|c|c|c|c|}
\hline & $\begin{array}{l}\text { Representation } \\
\text { of Practice in } \\
\text { PF Focus Groups } \\
(n=81), n(\%)\end{array}$ & $\begin{array}{l}\text { No Representation } \\
\text { of Practice in } \\
\text { PF Focus Groups } \\
(n=33), n(\%)\end{array}$ & $\begin{array}{c}P \\
\text { Value }\end{array}$ \\
\hline Practice size & & & .58 \\
\hline Solo practice & $22(28)$ & $12(37)$ & \\
\hline 2-5 clinicians & $38(48)$ & $15(46)$ & \\
\hline$\geq 6$ clinicians & $20(25)$ & $6(18)$ & \\
\hline Practice ownership ${ }^{b}$ & & & .06 \\
\hline $\begin{array}{l}\text { Clinician-Owned solo or group } \\
\text { practice }\end{array}$ & $30(41)$ & $10(42)$ & \\
\hline Hospital/health system owned & $28(38)$ & $4(17)$ & \\
\hline $\begin{array}{l}\text { Federally Qualified Health } \\
\text { Center or look-alike }\end{array}$ & $13(18)$ & $10(42)$ & \\
\hline $\begin{array}{l}\text { Other or more than } 1 \text { type of } \\
\text { ownership }\end{array}$ & $3(4)$ & $0(0)$ & \\
\hline Practice specialty & & & .02 \\
\hline Single specialty & $49(74)$ & $10(48)$ & \\
\hline Multi specialty & $17(26)$ & $11(52)$ & \\
\hline $\begin{array}{l}\text { Practice designated as a MUA } \\
\text { or MUP }\end{array}$ & $24(31)$ & $15(47)$ & .11 \\
\hline$\geq 100$ patient visits per week ${ }^{c}$ & $45(63)$ & $16(73)$ & .38 \\
\hline \multicolumn{4}{|l|}{ Staff composition } \\
\hline$>3$ clinicians (MD, DO, NP, PA) & $23(32)$ & $5(22)$ & .37 \\
\hline $\begin{array}{l}>3 \text { clinical staff members } \\
(\mathrm{RN}, \mathrm{LPN}, \mathrm{MA}, \mathrm{CMA})\end{array}$ & $31(43)$ & $12(55)$ & .32 \\
\hline $\begin{array}{l}>3 \text { office staff members } \\
\text { (eg, receptionist) }\end{array}$ & $31(44)$ & $8(35)$ & .42 \\
\hline \multicolumn{4}{|c|}{$\begin{array}{l}\mathrm{CMA}=\text { certified medical assistant; } \mathrm{DO}=\text { doctor of osteopathic medicine; } \mathrm{H} 3=\text { Healthy Hearts in the Heart- } \\
\text { land; } \mathrm{LPN}=\text { licensed practical nurse; } \mathrm{MA}=\text { medical assistant; } \mathrm{MD}=\text { doctor of medicine; } \mathrm{MUA}=\text { medically } \\
\text { underserved area; } \mathrm{MUP}=\text { medically underserved population; } \mathrm{NP}=\text { nurse practitioner; } \mathrm{PA}=\text { physician assis- } \\
\text { tant; } \mathrm{PF}=\text { practice facilitator; } \mathrm{PM}=\text { population management; } \mathrm{POC}=\text { point of care; } \mathrm{RN}=\text { registered nurse. } \\
\text { a Numbers may not equal } 114 \text { due to missing data. } \\
\text { b Fisher's exact test used. } \\
\text { 'Estimated. }\end{array}$} \\
\hline
\end{tabular}

Practice facilitators perceived that some practice staff gained new resource knowledge from the HealtheRx-H3. While reviewing HealtheRxH3 with a practice manager, PF3 recalled: "A lot of the times they [staff] were seeing some of these resources for the first time. 'Oh I didn't know that... there were 2 pharmacies within a mile.' ... 'Oh they have a blood pressure machine at this, you know, pharmacy? I'm gonna refer patients there. I just had someone ask about that.' So, it was actually you know, enlightening..." Practice facilitators observed that some practices customized delivery of the HealtheRx-H3, for example, by laminating it (to minimize printing) or posting it in a high-traffic area and instructing patients to take a picture of it. One practice created a large poster of the HealtheRx-H3 and posted it in the waiting room.

Conversely, 6 practice facilitators indicated that 1 or a few of their assigned practices had more negative attitudes about making community referrals to promote heart health due to beliefs that the community lacked resources, or skepticism that patients would utilize or could not access referred resources. Two practice facilitators (PF1, PF7) stated that the HealtheRx-H3 was perceived at a few practices as "another piece of paper." Practice facilitators did not hear clinicians or staff at these practices explicitly state that they would not deliver the HealtheRx-H3, but rather expressed an "overall politeness" (PF4) and were noncommittal when practice facilitators inquired about the intervention. PF13 said, "I got a lot of shrugging."

\section{Facilitators of and Barriers to Connecting Patients to Community Resources in Small Primary Care Practices}

Practice facilitators identified a clinician champion (either a physician or nurse practitioner) as the main facilitator of implementation of CommunityRx-H3. 
The champion signaled organizational buy-in to others and motivated adoption. Practice facilitators noted that engaged clinic and practice managers were also important facilitators of implementation. PF2 recalled, "Any of my clinics that were eligible for this tool, it wasn't a new concept to them. They did seem to like it better once they could customize it. And that was typically done through their clinic manager or office manager," who would then make sure the clinician delivered the HealtheRx-H3 to patients. Additionally, practice facilitators reported that practices perceived as "community health centers" had a practice culture that valued community resource referrals for care coordination. Practice facilitators perceived that staff at these practices were accustomed to referring patients to community resources, and these practices seemed more likely to implement the intervention as a tool to address patient heart health. Responding to why community health centers seemed more "in touch with the community resources," PF5 stated, "I think it's just more in the nature of the way they have grown up delivering services, [name of community health center] are more comprehensive, whereas [other practice name] was really a medical practice."

Nine practice facilitators perceived clinician or staff apathy as the main barrier to CommunityRx-H3 implementation: "If it's not a priority to the doctor, the rest of the staff is gonna say, 'thanks but no thanks."' (PF5). Other barriers identified by practice facilitators included limited staff capacity to complete the resource inventory, time to deliver the HealtheRx-H3 to patients, and availability and cost of paper and printing materials to generate the HealtheRx-H3. Of note, the first 2 waves of enrolled practices $(n=82)$ were expecting integration of CommunityRx-H3 with their EMR platforms. Practice facilitators largely agreed that lack of EMR integration, especially among practices that were expecting it, coupled with clinicians' resistance to change (even among practices that were already making community resource referrals), created some pushback from practice clinicians and staff.

\section{Practice Facilitator Strategies to Encourage CommunityRx-H3 Implementation}

In addition to the strategies practice facilitators were trained to employ, practice facilitators introduced 3 additional strategies to encourage implementation of CommunityRx-H3. First, practice facilitators were responsive to practices' requests for iteration of the HealtheRx-H3. PF11, describing her interactions with a practice, states, "You did the inventory on that... and once they saw the visual they said, 'Oh! Let's put in our pharmacy that is now down the street. Oh, and let's remove that because we actually now use this organization for the mental health therapy."' Practices' change requests to practice facilitators were then relayed to research staff who made updates and some PFs noted that practices "did appreciate the ability to customize." Second, practice facilitators observed practice workflows to help identify health care staff best positioned to deliver the HealtheRx-H3. For example, PF14 observed, "If you have... maybe a nurse or an MA [medical assistant] that... as the patient exits-'Okay, Mrs. Smith, these are the things you need to do and.. this is where you exercise, these are your pharmacies where they do free blood pressure checks."' Practice facilitators also provided suggestions about where the practice could place the printed HealtheRx-H3s to maximize distribution. Last, practice facilitators provided material support by providing printed copies of the HealtheRx-H3 for practices where materials or cost were barriers.

\section{Strategies for Optimization of CommunityRx-H3 Implementation}

Practice facilitators offered several ideas about how to optimize implementation of Community Rx-H3 in small primary care practices. Practice facilitators widely agreed that integrating Healthe $\mathrm{Rx}-\mathrm{H} 3$ generation into EMR workflows would reduce workflow complexity and make delivery more systematic. Some practice facilitators suggested using telephone applications or patient portals to facilitate access to the HealtheRx$\mathrm{H} 3$, although others were skeptical about patients' use of portals. There was strong agreement that impact of the intervention on CVD outcomes would be limited if delivery of the HealtheRx-H3 was not accompanied by communication between a clinician and the patient about the importance of using community resources. This idea is exemplified in an exchange between 2 practice facilitators:

"We were thinking that the doctor really needs to be the one to relay the importance of what's on the document, and it doesn't really matter who gives the patient the document. But if the doctor tells the patient 'I'm gonna give you a few resources about this and I want you to follow up on this,' then it doesn't matter who it comes from in that office. Because the patient, you know, they hear it from the doctor." (PF1)

"Patients are still looking to doctors for the 'What am I supposed to do?' I mean, and in some cases, you know, it could be an NP [nurse practitioner] or an educator, someone that they're used to working with. The piece of paper isn't nearly as important as somebody saying 'this is important."' (PF5)

Practice facilitators also reflected on design of the implementation process. Practices were first asked to complete the resource inventory. Then, the practicespecific HealtheRx-H3 was generated and presented to 
practice staff for feedback and further customization. Several practice facilitators noted that once practices saw their initial HealtheRx-H3 they had "a better sense of what the end goal was of that inventory," and "to really see the benefit" (PF9). Retrospectively, practice facilitators felt the implementation process would have worked better if they had shown practices a generic HealtheRx-H3, similar to the one used during training, at the practice kick-off meetings. Practice facilitators reflected that it could have been used to help motivate and guide completion of the resource inventory.

\section{DISCUSSION}

This study finds that many of the small and mid-size primary care practices enrolled in $\mathrm{H} 3$ already used nonsystematic strategies for connecting patients to healthrelated community resources. When presented with the QI opportunity to implement a standard, CVD-specific strategy for delivering community resource information to patients, more than one-half of practices randomized to the study arm that included CommunityRx-H3 either completed the inventory or requested customization of their HealtheRx-H3. ${ }^{28}$ CommunityRx-H3 implementation and observations essential to this implementation science analysis were led by trained practice facilitators, a growing role in primary care practice improvement. To our knowledge, the current study is one of the first to investigate practice facilitators' perceptions and observations of implementation of a QI intervention to connect patients to community resources for heart health, the most understudied component of the Chronic Care Model. ${ }^{17}$ This study demonstrates, as has been shown previously, 9,10,15,38 the value of the practice facilitator role for both QI process implementation and implementation research.

Practice facilitator perceptions of facilitators and barriers to the CommunityRx-H3 implementation process corroborate findings from prior studies of practice facilitator-led primary care QI efforts for CVD care $^{38-41}$ Facilitators included engaged champions and opinion leaders at the practice, both constructs identified in the CFIR process domain. ${ }^{30}$ Practice culture, an inner-setting construct in the CFIR, was also identified by practice facilitators as a facilitator to implementation. In alignment with the characteristics of individuals domain of the CFIR, the main implementation barrier was clinician apathy, described by practice facilitators as lacking knowledge about CVD-related community resources and negative beliefs about the degree to which such resources could benefit patients. Prior studies indicate that engaged practice champions, especially clinicians, are critical to small primary care practices' QI implementation success. ${ }^{39,42}$ Conversely, external practice facilitation has had limited impact in settings where key practice leaders were resistant to change, deflected, or shut down communication among the practice staff or only superficially supported implementation efforts. ${ }^{12,14}$

Practices' unwillingness to integrate the intervention into existing workflows (coupled with clinician apathy) and limited staff capacity to complete the resource inventory were barriers that could be addressed with EMR integration of the community resource referral tool. EMR integration, a central component of the CommunityRx intervention achieved in several other contexts, ${ }^{21,23}$ was infeasible in this study due to inconsistent EMR conditions and legal contracting processes, among other reasons. While not generated by the focus groups, these operational processes represent inner and outer setting constructs, ${ }^{30}$ respectively, that are important to consider when implementing QI efforts in small primary care practices. A shift in strategy from EMR integration to a manual workflow was informed and made possible by practice facilitator observations and creativity with the practices they served. Practice facilitators in a similar study found that remaining flexible was a main strategy used to lead QI implementation efforts at small primary care practices. ${ }^{38}$ The manual workflow enabled practicelevel customization of the information on and delivery of the HealtheRx-H3 to patients, which practice facilitators leveraged to promote engagement and adoption. Although the manual approach is less scalable and trackable than the previously demonstrated EMR-integrated approach, standardizing community resource information for CVD prevention and management yielded some relative advantage (a characteristic of the "intervention characteristics" domain of the CFIR) over historical ad hoc procedures (eg, community resource knowledge gains among clinicians). Consistent with these findings, a systematic review and meta-analysis of primary care practices' use of practice facilitation found that QI interventions that were tailored to the practice by practice facilitators were more likely to be implemented successfully. ${ }^{9}$

These findings should be considered in light of certain limitations. Firsthand experiences and attitudes of clinicians and staff at participating $\mathrm{H} 3$ practices were not elicited; however, the use of practice facilitators as expert informants is appropriate in this study as they were "on the ground" during the implementation period and responsible for responding to implementation challenges experienced by $\mathrm{H} 3$ practices. Practice facilitators, as intermediaries for reporting practice staff observations, may have been less susceptible to acquiescence bias, where respondents tend to answer positively to the questions at hand despite the true 
response being negative; however, this is more of an issue in conventional survey research. While directed content analysis was informed by evidence from prior CommunityRx implementations and has the advantage of focusing the research question and the initial coding schema, the use of structured, targeted questions may yield a narrower set of perspectives than a more open-ended approach. In addition, not all $\mathrm{H} 3$ practices randomized to the $\mathrm{POC}+\mathrm{PM}$ arm were represented by practice facilitators participating in the focus groups, but practice-level characteristics were largely similar among practices that were and were not represented. Lastly, CommunityRx-H3 was one of 35 QI strategies available to practices in this study ${ }^{6}$ i thus tailored practice facilitator support for any one of the strategies was quite limited. CommunityRx-H3 implementation may have benefitted from more guided coaching to support adoption, leading to better buy-in from practice leadership.

\section{CONCLUSION}

Practice facilitators are increasingly engaged by primary care practices to support QI interventions and, in certain contexts, demonstrate value in their ability to support quality improvement and evidence-based practice methods. As shown here, practice facilitators can also play an important role in implementation science, but the importance of effective and engaged practice leadership cannot be overemphasized. This study yields both practice- and practice facilitatorlevel insights to improve implementation of community resource referral solutions to support primary care CVD prevention efforts, an important and understudied component of evidence-based CVD care.

\section{To read or post commentaries in response to this article, see it} online at https://www.AnnFamMed.org/content/18/6/486.

Submitted September 26, 2019; submitted, revised, February 13, 2020; accepted March 9, 2020.

Key words: practice facilitation; quality improvement; community resource referrals; implementation science; qualitative research

Funding support: This project was supported by the Agency for Healthcare Research and Quality (AHRQ R18HS023921).

Prior presentations: CommunityRx-H3: Promoting Healthy Hearts in the Heartland $(\mathrm{H} 3)$ by systematizing referrals to community-based resources for diabetes and hypertension self-management presented at the Society of General Internal Medicine 2018 Midwest Annual Meeting; September 13, 2018; Chicago, Illinois and presented as poster at Annual Meeting of the North American Primary Care Research Group; November 10, 2018; Chicago, Illinois, and presented as poster at Academy Health $11^{\text {th }}$ Annual Conference on the Science of Dissemination and Implementation in Health; December 3, 2018; Washington, DC, and Implementing community resource referrals for CVD: insights from practice facilitators presented as poster at the Illinois Public Health Association 78th Annual Conference: Healthy by Design; September 12, 2019; Springfield, Illinois.
Supplemental materials: Available at https://www.AnnFamMed. org/content/18/6/486/suppl/DC1/.

\section{References}

1. Frieden TR, Berwick DM. The "Million Hearts" initiative-preventing heart attacks and strokes. N Engl J Med. 2011;365(13):e27.

2. Department of Health and Human Services. About Million Hearts. Million Hearts. https://www.millionhearts.hhs.gov/about-millionhearts/index.html. Accessed May 3, 2019.

3. Rittenhouse DR, Ramsay PP, Casalino LP, McClellan S, Kandel ZK, Shortell SM. Increased health information technology adoption and use among small primary care physician practices over time: a national cohort study. Ann Fam Med. 2017;15(1):56-62.

4. Cuellar A, Krist AH, Nichols LM, Kuzel AJ. Effect of practice ownership on work environment, learning culture, psychological safety, and burnout. Ann Fam Med. 2018;16(Suppl 1):S44-S51.

5. Meyers D, Miller T, Genevro J, et al. EvidenceNOW: balancing primary care implementation and implementation research. Ann Fam Med. 2018;16(Suppl 1):S5-S11.

6. Ciolino JD, Jackson KL, Liss DT, et al. Design of healthy hearts in the heartland (H3): a practice-randomized, comparative effectiveness study. Contemp Clin Trials. 2018;71:47-54.

7. James, Julia. Pay-for-Performance. Health Affairs. https://www. healthaffairs.org/do/10.1377/hpb20121011.90233/full/healthpolicy brief_78.pdf. Published Oct 11, 2012. Accessed May 3, 2019.

8. Parekh A, Schreiber R. How community-based organizations can support value-driven health care. https://www. healthaffairs.org/ do/10.1377/hblog20150710.049256/full/. Published Jul 10, 2015. Accessed May 3, 2019.

9. Baskerville NB, Liddy C, Hogg W. Systematic review and metaanalysis of practice facilitation within primary care settings. Ann Fam Med. 2012;10(1):63-74.

10. Taylor EF, Machta RM, Meyers DS, Genevro J, Peikes DN. Enhancing the primary care team to provide redesigned care: the roles of practice facilitators and care managers. Ann Fam Med. 2013;11(1): 80-83.

11. Agency for Healthcare Research and Quality. Practice facilitation. PCMH Resource Center. https://pcmh.ahrq.gov/page/practicefacilitation. Accessed Dec 16, 2019.

12. Balasubramanian BA, Chase SM, Nutting PA, et al; ULTRA Study Team. Using learning teams for reflective adaptation (ULTRA): insights from a team-based change management strategy in primary care. Ann Fam Med. 2010;8(5):425-432.

13. Dickinson WP, Dickinson LM, Nutting PA, et al. Practice facilitation to improve diabetes care in primary care: a report from the EPIC randomized clinical trial. Ann Fam Med. 2014;12(1):8-16.

14. Shaw EK, Ohman-Strickland PA, Piasecki A, et al. Effects of facilitated team meetings and learning collaboratives on colorectal cancer screening rates in primary care practices: a cluster randomized trial. Ann Fam Med. 2013;11(3):220-228, S1-8.

15. Wang A, Pollack T, Kadziel LA, et al. Impact of practice facilitation in primary care on chronic disease care processes and outcomes: a systematic review. J Gen Intern Med. 2018;33(11):1968-1977.

16. Hemler JR, Hall JD, Cholan RA, et al. Practice facilitator strategies for addressing electronic health record data challenges for quality improvement: EvidenceNOW. J Am Board Fam Med. 2018;31(3): 398-409.

17. Pearson ML, Wu S, Schaefer J, et al. Assessing the implementation of the chronic care model in quality improvement collaboratives. Health Serv Res. 2005;40(4):978-996. 10.1111/j.1475-6773.2005. 00397.x.

18. Bodenheimer T, Lorig K, Holman $H$, Grumbach K. Patient self-management of chronic disease in primary care. JAMA. 2002;288(19): 2469-2475. 
19. Agency for Healthcare Research and Quality. EvidenceNOW: advancing heart health in primary care. Agency for Healthcare Research \& Quality. https://www.ahrq.gov/evidencenow/index.html. Accessed May 9, 2019.

20. Agency for Healthcare Research and Quality. Skills for working with practices. https://www.ahrq.gov/evidencenow/tools/facilitation/ index.html. Accessed Dec 16, 2019.

21. Lindau ST, Makelarski J, Abramsohn E, et al. CommunityRx: a population health improvement innovation that connects clinics to communities. Health Aff (Millwood). 2016;35(11):2020-2029.

22. Tung E, Abramsohn EM, Boyd K, et al. Impact of the CommunityRx intervention on patients' knowledge, beliefs, and use of community resources: Results from a pragmatic controlled trial. J Gen Intern Med. In press.

23. Lindau ST, Makelarski JA, Abramsohn EM, et al. CommunityRx: a real-world controlled clinical trial of a scalable, low-Intensity community resource referral intervention. Am J Public Health. 2019; 109(4):600-606.

24. Berkowitz SA, Hulberg AC, Standish S, Reznor G, Atlas SJ. Addressing unmet basic resource needs as part of chronic cardiometabolic disease management. JAMA Intern Med. 2017;177(2):244-252.

25. Garg A, Toy S, Tripodis Y, Silverstein M, Freeman E. Addressing social determinants of health at well child care visits: a cluster RCT. Pediatrics. 2015;135(2):e296-e304. 10.1542/peds.2014-2888.

26. Gottlieb LM, Wing $H$, Adler NE. A Systematic review of interventions on patients' social and economic needs. Am J Prev Med. 2017; 53(5):719-729.

27. Cartier Y, Fichtenberg C, Gottlieb L. Community Resource Referrals Platforms: A Guide for Health Care Organizations. San Francisco, CA: SIREN; 2019. https://sirenetwork.ucsf.edu/sites/sirenetwork.ucsf.edu/ files/wysiwyg/Community-Resource-Referral-Platforms-Guide.pdf. Accessed Jul 10, 2019.

28. Makelarski JA, DePumpo M, Boyd K, et al. Implementation of systematic community resource referrals at small primary care practices to promote cardiovascular disease self-management. [published online ahead of print Nov 20, 2019]. J Healthe Qual. doi: 10.1097/ JHQ.0000000000000234.

29. Ploeg J, Denton M, Hutchison B, et al. Primary care physicians' perspectives on facilitating older patients' access to community support services: qualitative case study. Can Fam Physician. 2017;63(1): e31-e42.
30. Damschroder LJ, Aron DC, Keith RE, Kirsh SR, Alexander JA, Lowery JC. Fostering implementation of health services research findings into practice: a consolidated framework for advancing implementation science. Implement Sci. 2009:4:50.

31. Persell SD, Liss DT, Walunas TL, et al. Effects of two forms of practice facilitation on cardiovascular prevention in primary care: a practice-randomized, comparative effectiveness trial. Med Care. 2020;58(4):344-351.

32. Oh A, Chou WS, Jackson D, et al. Reducing cancer disparities through community engagment: the promise of informatics. In: Hesse BW, Ahern DK, Beckjord E, eds. Oncology Informatics. San Diego, CA: Elsevier Inc; 2016:23-39.

33. Kitzinger J. Qualitative research; introducing focus groups. BMJ. 1995;311(7000):299-302.

34. Guest G, Namey E, McKenna K. How many focus groups are enough? Building an evidence base for nonprobability sample sizes. Field Methods. 2017;29(1):3-22.

35. Hsieh H-F, Shannon SE. Three approaches to qualitative content analysis. Qual Health Res. 2005;15(9):1277-1288.

36. Onwuegbuzie AJ, Dickinson WB, Leech NL, Zoran AG. A qualitative framework for collecting and analyzing data in focus group research. Int J Qual Methods. 2009;8(3):1-21.

37. Guest $G$, Bunce $A$, Johnson L. How many interviews are enough? An experiment with data saturation and variability. Field Methods. 2006;18(1):59-82.

38. Nguyen AM, Cuthel A, Padgett DK, et al. How practice facilitation strategies differ by practice context. J Gen Intern Med. 2020;35(3): 824-831.

39. McHugh M, Brown T, Liss DT, Walunas TL, Persell SD. Practice facilitators' and leaders' perspectives on a facilitated quality improvement program. Ann Fam Med. 2018;16(Suppl 1):S65-S71.

40. Liddy CE, Blazhko V, Dingwall M, Singh J, Hogg WE. Primary care quality improvement from a practice facilitator's perspective. BMC Fam Pract. 2014;15(23):23.

41. Liddy C, Rowan M, Valiquette-Tessier SC, Drosinis P, Crowe L, Hogg W. Improved delivery of cardiovascular care (IDOCC): findings from narrative reports by practice facilitators. Prev Med Rep. 2016;5(5): 214-219.

42. Goetz Goldberg D, Haghighat S, Kavalloor S, Nichols LM. A qualitative analysis of implementing EvidenceNOW to improve cardiovascular care. J Am Board Fam Med. 2019;32(5):705-714. 